\title{
Characterization of hematite sols: correlation of size, shape and percentage yield
}

\author{
P D SAWANT \\ Chemistry Division, Bhabha Atomic Research Centre, Mumbai 400 085, India \\ MS received 13 October 1995; revised 27 June 1996
}

\begin{abstract}
Fe}_{2} \mathrm{O}_{3}$ sols were prepared by forced hydrolysis method. The effect of time of aging, concentrations of ferric chloride and hydrochloric acid on the size, shape and percent yield were studied. Static light scattering was employed to determine the spherical shape, further confirmed by cryo-SEM technique.
\end{abstract}

Keywords. Hematite sols; forced hydrolysis; light scattering; cryo-SEM.

\section{Introduction}

The method of preparation of hematite sols of submicron size using forced hydrolysis technique was pioneered by Matijevic and Scheiner (1978). This method was further modified by Penner and Koopal (1986) for preparation of larger size, monodispersed sols on the small seed particles of the same sol. Microemulsion media have also been employed to prepare particles of sizes below $100 \mathrm{~nm}$ (Ayyub et al 1988). Spectral, physicochemical (Morris et al 1985), photocatalytic (Henglein 1987), magnetic (Muench et al 1981) and catalytic (Nozawa and Yoneda 1980) properties of $\alpha-\mathrm{Fe}_{2} \mathrm{O}_{3}$ have been studied by several authors. It is known that the morphology and size of the particles depend on several factors such as $\mathrm{pH}$, concentration of reactants, nature of medium, time and temperature of aging and nature of anion present in reactant salt solutions (Murphy et al 1976; Sugimoto and Matijevic 1980; Hamada and Matijevic 1982; Ozaki et al 1984, 1990; De Blanko et al 1986; Hamada and Matijevic 1990; Morales et al 1992; Baily et al 1993; Okana et al 1995). But a clear relationship between the reaction conditions and morphology of hematite particles has not emerged and their preparation remained an art.

In view of important applications of hematite in industry (Matijevic 1984), it is also necessary to evaluate the methods of preparation with percentage yield of formation in addition to size and shape. Therefore in the present paper, hematite sols prepared under different conditions were characterized with respect to size, shape and percentage yield of formation.

\section{Experimental}

\subsection{Materials}

Ferric chloride and hydrochloric acid used were of AR grade. Stock solutions were prepared using nanopure water and were filtered through $0.2 \mu$ milli-Q filter paper before reaction. 


\subsection{Procedures}

Size of hematite sols were measured using particle sizer (Brookhaven Instrument model B1-90) based on the principle of dynamic light scattering. Static light scattering experiments were performed on Brice-Phoenix Light Scattering Photometer using a source of $5 \mathrm{~mW} \mathrm{He} / \mathrm{Ne}$ laser light of wavelength $0.6328 \mu$. Rayleigh-Gann theory in conjunction with Guinier law and $P(Q)$ formula for spherical particle was used to assess the shape and size of $\alpha-\mathrm{Fe}_{2} \mathrm{O}_{3}$. These experiments were performed by taking sols in a round glass cell which was kept at the toluene bath to match the refractive indices glass and water. Scattered intensities were measured between angles 30 to $130^{\circ}$ with respect to incident laser beam. The shapes obtained were independent of the size of particles. X-ray diffraction patterns were recorded on Philips X-ray diffractometer. Shapes of particles were monitored using fast-freeze-fracture technique of cryo-SEM on JEOL-JSM6400 model. When a sol sandwitched between two copper grids was plunged into the liquid freon, the sol got frozen at a rate of $10,000^{\circ} \mathrm{K} / \mathrm{sec}$. Due to fast freezing of the sol all motions of particles stopped instantaneously and thus it was possible to monitor the particles without any agglomeration. By fracturing of the upper grid it is possible to view the particles. Thus it avoids the drawbacks of drying methods.

Percentage yields were calculated from weight difference of filter paper alone and hematite deposited filter paper. The hematite sols were filtered through $0.05 \mu$ or $0.22 \mu$ milli-Q filter papers and were dried in an oven at $70^{\circ} \mathrm{C}$, kept in desiccator to attain room temperature. The average of three readings were taken into consideration.

\subsection{Preparation conditions}

The sols were prepared using the method described by Matijevic (1985) under the following conditions:

(I) Time of aging was varied from 6 to $48 \mathrm{~h}$; keeping $\mathrm{FeCl}_{3}$ and $\mathrm{HCl}$ concentrations fixed as $20 \mathrm{mM}$ and $3 \mathrm{mM}$ respectively.

(II) Four sets of solutions of $10 \mathrm{mM}, 15 \mathrm{mM}, 25 \mathrm{mM}$ and $30 \mathrm{mM} \mathrm{FeCl}_{3}$ were mixed with different concentrations of $\mathrm{HCl}$ and aged to $100^{\circ} \mathrm{C}$ for $24 \mathrm{~h}$ and then immediately quenched into cold water.

(III) Different concentrations of $\mathrm{FeCl}_{3}$ solutions were mixed with $10 \mathrm{mM} \mathrm{HCl}$ and aged at $100^{\circ} \mathrm{C}$ for $24 \mathrm{~h}$ and then immediately quenched into cold water.

\section{Results and discussion}

\subsection{Variation of aging time}

$\alpha-\mathrm{Fe}_{2} \mathrm{O}_{3}$ sols were prepared by aging $20 \mathrm{mM} \mathrm{FeCl}_{3}$ and $3 \mathrm{mM} \mathrm{HCl}$ solutions and quenched at different time intervals. The sizes of sols increased up to $24 \mathrm{~h}$ of aging and a saturation in size (figure 1) was observed later up to $48 \mathrm{~h}$. This type of behaviour was previously observed for mixed oxides of cadmium and nickel particles (Quiben and Matijevic 1994) and for ellipsoidal hematite sol prepared from ferric nitrate and nitric acid (Okana et al 1995). The above behaviour indicates the aggregation of the particles with aging time. 


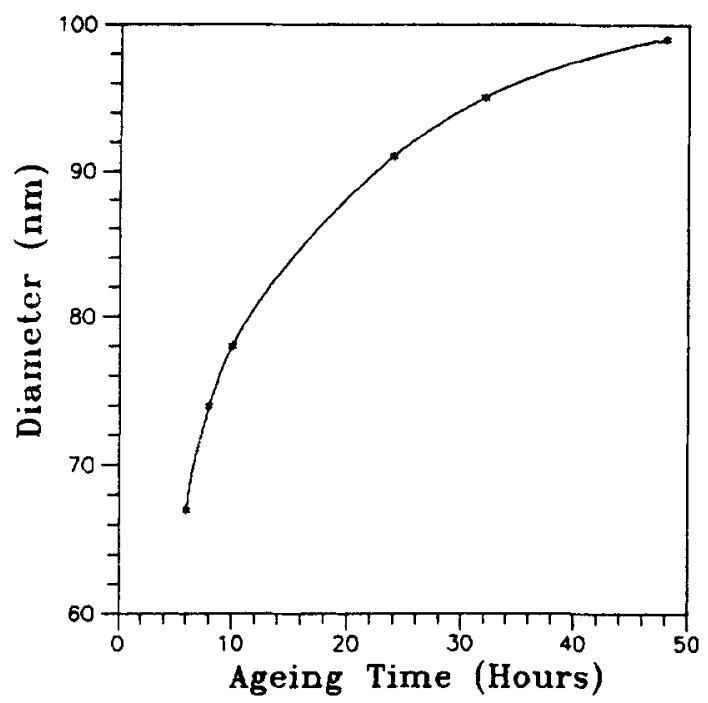

Figure 1. Time of aging vs diameter of particles.

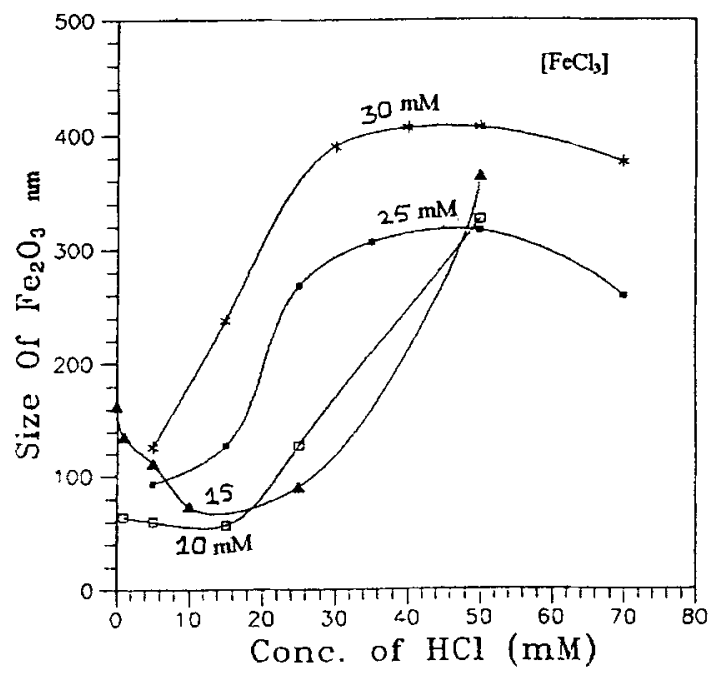

Figure 2. Concentration of $\mathrm{HCl}$ vs diameter of $\alpha-\mathrm{Fe}_{2} \mathrm{O}_{3}$.

\subsection{Variation of concentration of $\mathrm{HCl}$}

(A) $\alpha-\mathrm{Fe}_{2} \mathrm{O}_{3}$ sols were prepared by aging solutions of $15 \mathrm{mM}$ ferric chloride with different concentrations of hydrochloric acid at $100^{\circ} \mathrm{C}$ for $24 \mathrm{~h}$. No sol formation was observed for $\mathrm{HCl}$ concentrations $80 \mathrm{mM}$ and above. This can be attributed to the excess concentration of $\mathrm{HCl}$ which suppressed the hydrolysis reaction (figures 2 and 3 ). Figure 2 shows the diameter of particles as a function of concentration of $\mathrm{HCl}$. The diameter of the products formed first decreased and was the lowest at $10-15 \mathrm{mM}$ of $\mathrm{HCl}$; the size increased with concentration of $\mathrm{HCl}$. In figure 3 percentage yields of the 


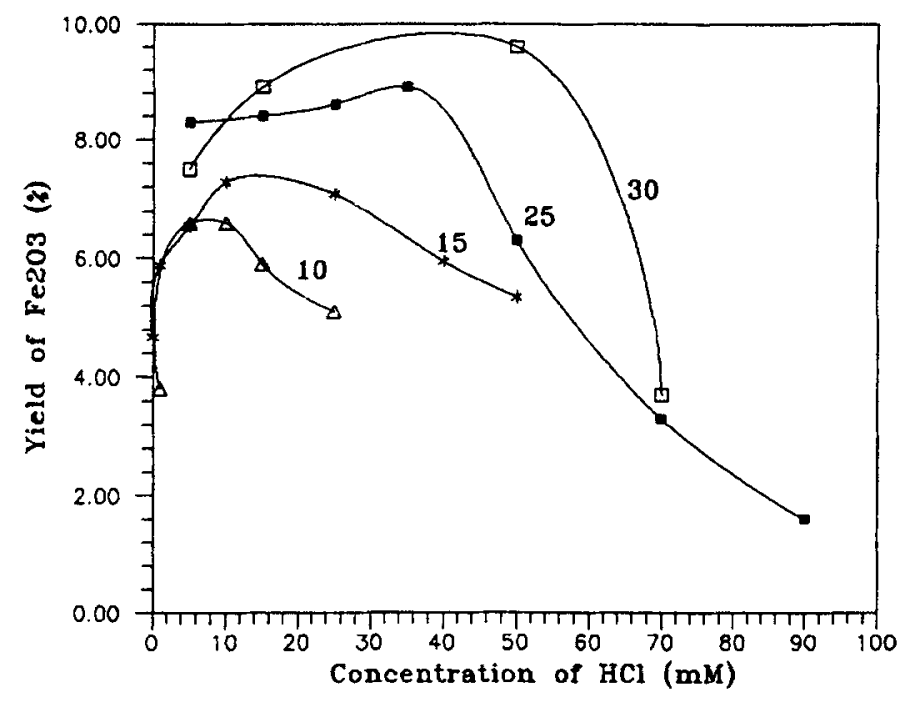

Figure 3. Concentration of $\mathrm{HCl}$ vs percentage yield.

product formed as a function of $\mathrm{HCl}$ concentration are shown. Percentage yields first increased and was the highest at $\mathrm{HCl}$ concentration of $10-15 \mathrm{mM}$ and then decreased. The above results indicate that the size was minimum with a maximum in percentage yield for $\mathrm{HCl}$ concentration of $10-15 \mathrm{mM}$. Figures $4 \mathrm{~A}-\mathrm{D}$ illustrate the morphology of $\alpha-\mathrm{Fe}_{2} \mathrm{O}_{3}$ obtained from cryo-SEM by fast freeze-fracture technique. Changes in shape of $\alpha-\mathrm{Fe}_{2} \mathrm{O}_{3}$ particles with concentration of $\mathrm{HCl}$ are indicated. The changes occurred in the morphology of $\alpha-\mathrm{Fe}_{2} \mathrm{O}_{3}$ were in the following order: somewhat triangular to cubic to sphere to ellipsoidal. Similar type of shapes were reported previously at different concentrations of both $\mathrm{FeCl}_{3}$ and $\mathrm{HCl}$ and in different media where sizes of the particles were also different and for which different mechanisms were suggested. Effect of $\mathrm{HCl}$ on the morphology of hematite particles were not fully established. Sphere and double-ellipsoid shapes were observed for $18 \mathrm{mM} \mathrm{FeCl}_{3}$ and $\mathrm{HCl}$ concentrations of $10 \mathrm{mM}$ and $50 \mathrm{mM}$ respectively by Matijevic and Scheiner (1978). Combining our results with the work of Matijevic and Scheiner (1978), the shapes of hematite particles were changed in the following order: somewhat triangular to cubes to sphere to ellipsoidal to double-ellipsoidal. Baily et al (1993) indicated different growth patterns for cubes. They attributed the formation of cubes to the high concentration of all ions as 30 -fold increase in the concentration of starting $\mathrm{FeCl}_{3}$. In the present study we have obtained the cubes between somewhat triangular and spheres. The cubes were obtained ralatively at low concentration of ferric chloride.

(B) A similar type of trends of size and percentage yield was observed when a set of sols prepared for various concentration of $\mathrm{HCl}$ for a fixed concentration of $\mathrm{FeCl}_{3}, 10 \mathrm{mM}$. Due to smaller sizes of particles it was not possible to check the gradual changes in shapes as observed in the first set. At high concentration of $\mathrm{HCl}(50 \mathrm{mM})$, ellipsoidal shaped particles (figure $4 \mathrm{E}$ ) were observed.

(C) When $\mathrm{FeCl}_{3}$ concentration was maintained constant, as $25 \mathrm{mM}$ and $30 \mathrm{mM}$, both size and yield increased and the highest yield was obtained for $\mathrm{HCl}$ concentration of 

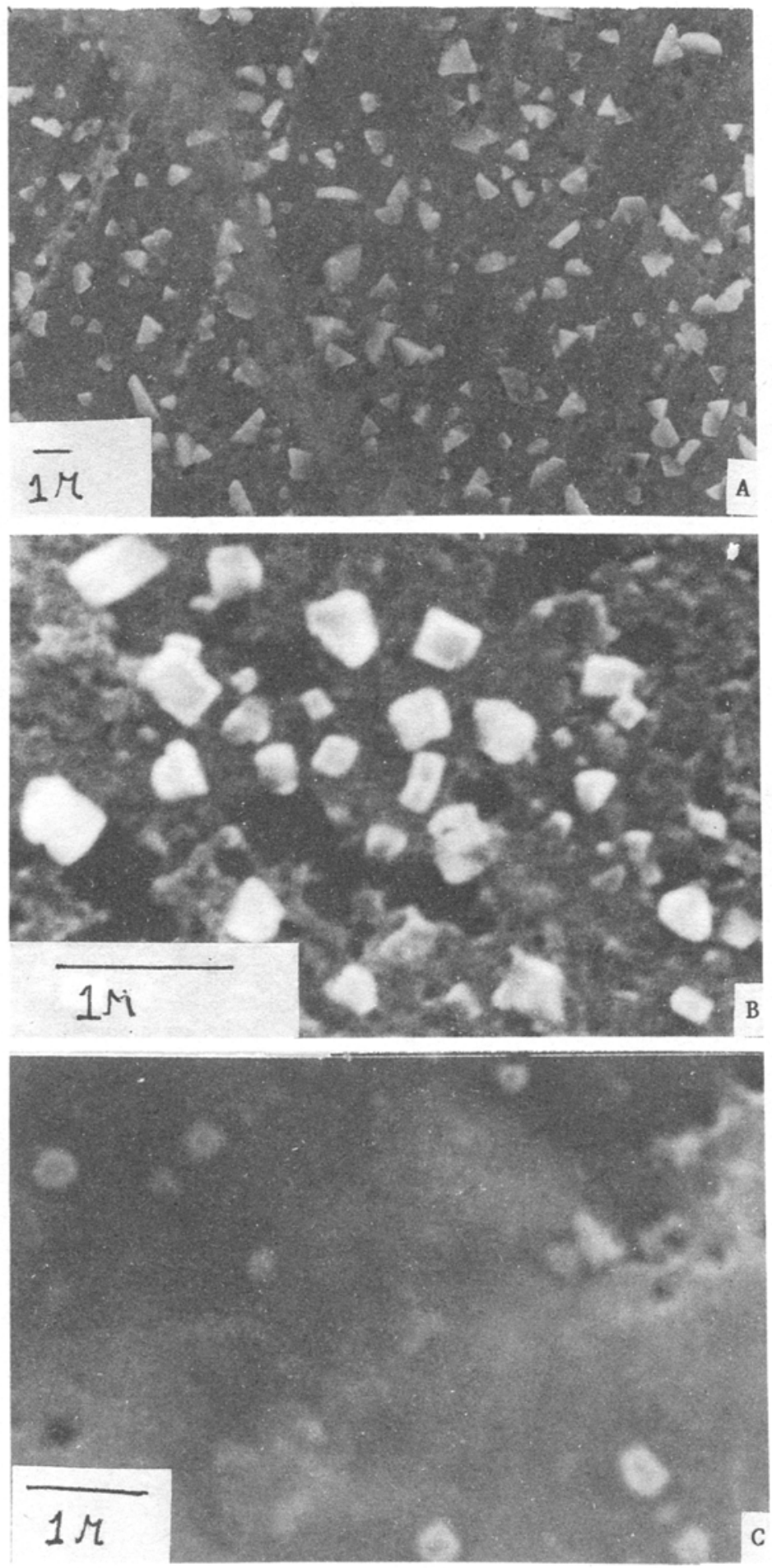

Figure 4. A-C. 

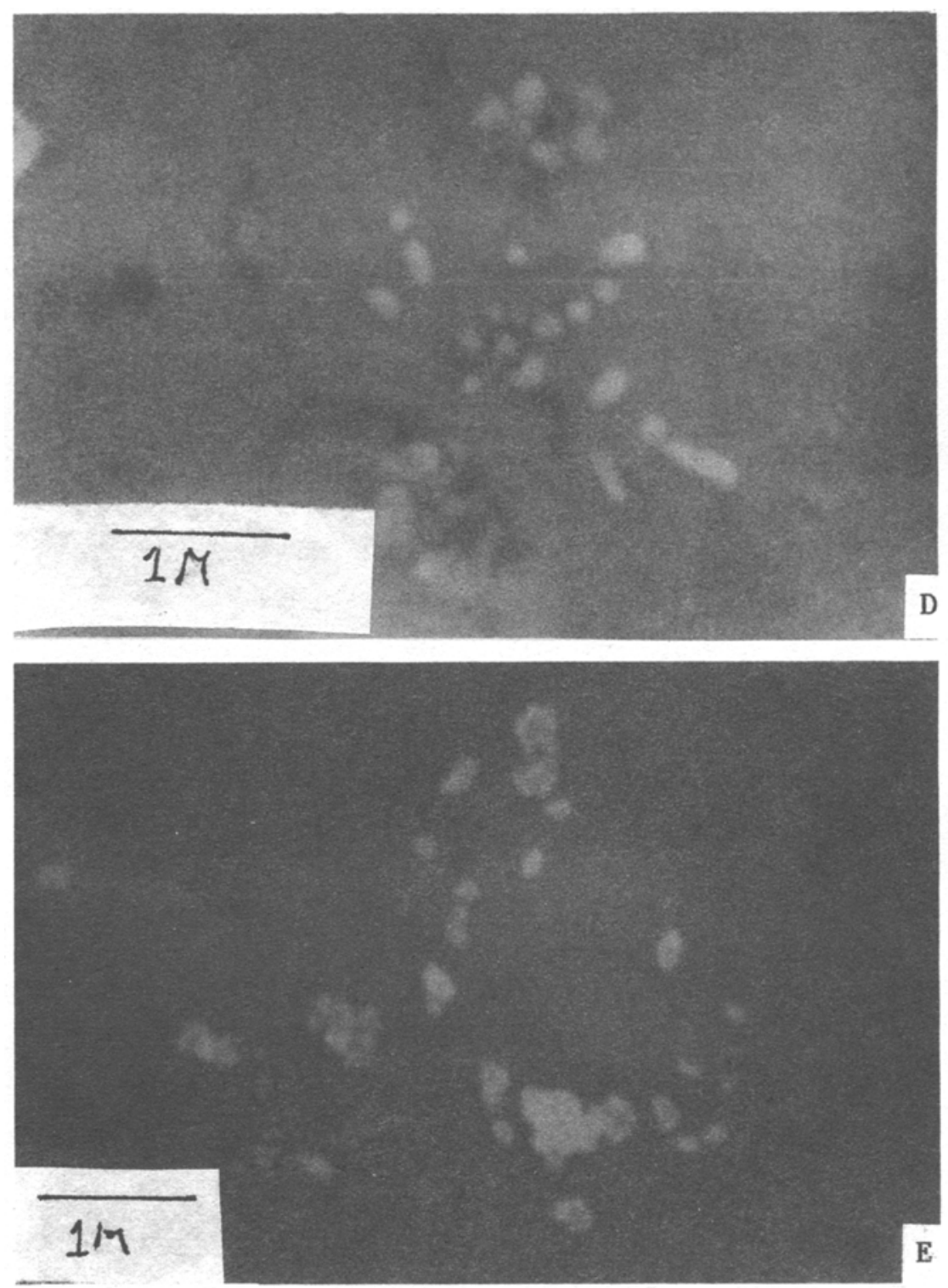

Figure 4. Cryo-SEM photographs of hematite particles observed in the sols prepared from $15 \mathrm{mM} \mathrm{FeCl}$ with increasing concentration of $\mathrm{HCl}$ (given in bracket): (A) somewhat triangular (1 mM),(B) cubic (10 mM),(C) spherical (10 mM), (D) ellipsoidal (25 mM) and (E) ellipsoidal shape obtained in sol prepared from $10 \mathrm{mM} \mathrm{FeCl}_{3}$ and $50 \mathrm{mM} \mathrm{HCl}$.

$35 \mathrm{mM}$ and $50 \mathrm{mM}$ respectively which then decreased as concentrations of $\mathrm{HCl}$ increased (figures 2 and 3). Decrease in size and increase in percentage yield at lower concentrations of $\mathrm{HCl}$ was not observed in these sets. Also the changes in shapes were not observed. This can be attributed to the increase in concentration of all the ions with the increase in concentration of $\mathrm{FeCl}_{3}$ which in turn affects the kinetics and mechanisms of formation. Spherical particles were formed in the above sets at following 
concentrations of ferric chloride and $\mathrm{HCl}$.

\begin{tabular}{ll}
\hline$\left[\mathrm{FeCl}_{3}\right]$ & {$[\mathrm{HCl}]$} \\
\hline $15 \mathrm{mM}$ & $10 \mathrm{mM}$ \\
$25 \mathrm{mM}$ & $35 \mathrm{mM}$ \\
$30 \mathrm{mM}$ & $50 \mathrm{mM}$ \\
\hline
\end{tabular}

Interestingly in all the above three sets, the percentage yield was found to be highest for spherical $\alpha-\mathrm{Fe}_{2} \mathrm{O}_{3}$, for which reasons are not yet known. Spherical shape was observed at high concentrations of $\mathrm{HCl}$ in $25 \mathrm{mM} \mathrm{FeCl}$ and $30 \mathrm{mM} \mathrm{FeCl}_{3}$ whereas in $15 \mathrm{mM} \mathrm{FeCl}_{3}$ it was observed at lower $\mathrm{HCl}$ concentration. The conversion of $\alpha-\mathrm{Fe}_{2} \mathrm{O}_{3}$ from $\mathrm{FeCl}_{3}$ in all these sets were found to be very low. The colour of the sols was observed to change from orange to red to yellowish with increase in the concentration of $\mathrm{HCl}$ and was reddish for the sol containing spherical particles.

\subsection{Variation in concentration of ferric chloride}

Concentration of ferric chloride was varied from $5 \mathrm{mM}$ to $40 \mathrm{mM}$ and $\mathrm{HCl}$ concentration was fixed at $10 \mathrm{mM}$. Both the size and percentage yield of the sols obtained showed a gradual increase with increase in concentration of $\mathrm{FeCl}_{3}$. Nonspherical shapes were observed by SEM at higher concentrations of $\mathrm{FeCl}_{3}$ except that of $15 \mathrm{mM}$ concentration.

Thus the changes in shapes as well as in yields were predominantly observed when $\mathrm{HCl}$ was varied. Thus it is possible to tune the morphology by changing only the concentration of $\mathrm{HCl}$. This suggests the requirement of suitable mechanisms which can explain changes in shapes of hematite. From the study of(II) and (III) it is observed that the yield of hematite is increased when $\mathrm{FeCl}_{3}$ concentration is equal to or more than the $\mathrm{HCl}$ concentration.

\subsection{Static light scattering}

In these experiments emphasis was given for the spherical shape of the particles in sols. Rayleigh-Gan (1983) theory in conjunction with Guinier law (Guinier 1939; Guinier and Fornet 1965), $P(Q)$, form factor formula (Aragon and Pecora 1976) and Schulz distribution law (Schulz 1935) were used to find out the spherical shape and size of the particles. Spherical shape can be observed from the curve nature in the plot of $Q^{2}$ vs $1 /$ (scattered intensity), where $Q$ is scattering wave vector. Polystyrene latex of size $300 \mathrm{~nm}$ was used as standard for these experiments. Static light scattering showed the gradual change in shape of $\alpha-\mathrm{Fe}_{2} \mathrm{O}_{3}$ with $\mathrm{HCl}$ concentrations for $\mathrm{FeCl}_{3}$ concentration of $30 \mathrm{mM}$ (figure 5). Similar trend is also observed for sols prepared from $25 \mathrm{mM} \mathrm{FeCl}_{3}$ and different concentration of $\mathrm{HCl}$, hence not shown here. Since it was difficult to measure the aspect ratio of ellipsoidal particles from SEM micrographs, hence the ellipsoidal shape was not considered in these experiments. The sizes obtained were in good agreement with light scattering results.

\section{Conclusions}

Thus overall findings of the above study can be summarized as follows:

(I) Hematite sols of different shapes can be obtained by varying the $\mathrm{HCl}$ concentration. 


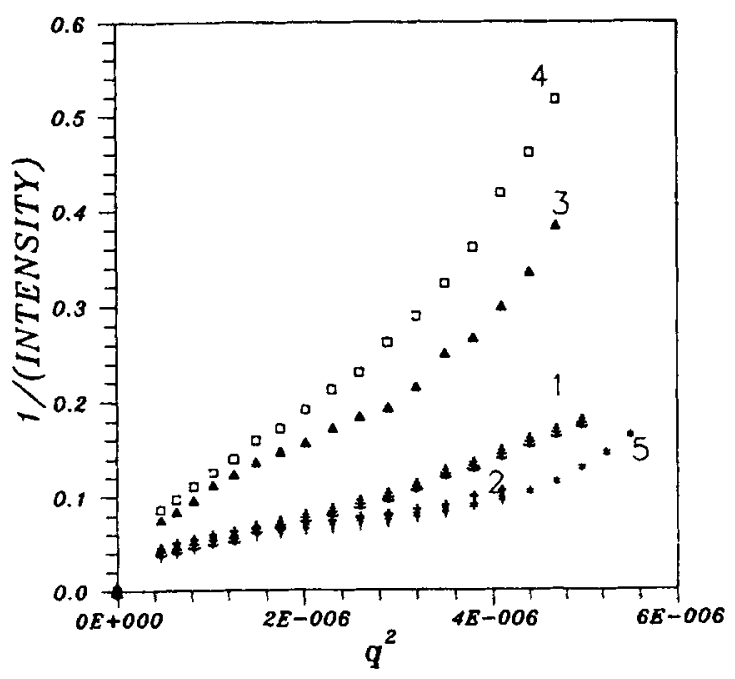

Figure 5. Plot of $Q^{2}$ vs 1 /(scattered intensity). Static light scattering shows the gradual change in shape of $\alpha-\mathrm{Fe}_{2} \mathrm{O}_{3}$. Concentration of $\mathrm{FeCl}_{3}$ is fixed at $30 \mathrm{mM}$. HCl concentrations used are: 1: $15 \mathrm{mM}, 2: 30 \mathrm{mM}, 3: 40 \mathrm{mM}, 4: 50 \mathrm{mM}, 5: 70 \mathrm{mM}$. Spherical shape can be observed from the curve nature in above plot.

(II) Comparison of above results with references (Baily et al 1993; Okana et al 1995) showed that the ellipsoidal particles were forming where $\mathrm{FeCl}_{3}$ concentration were much less than the concentration of $\mathrm{HCl}$ or $\mathrm{HNO}_{3}$.

(III) The percentage yields of hematite obtained from forced hydrolysis of $\mathrm{FeCl}_{3}$ were observed to be very low. High yiels can be obtained by increasing $\mathrm{FeCl}_{3}$ concentration but in turn it increases the size of hematite particles.

(IV) The yields obtained for hematite sols of spherical shape was observed to be higher than other shapes. The colour of these sols were observed to be reddish.

(V) Spherical particle formation and high yields were obtained when concentration of $\mathrm{HCl}$ was near to concentration of $\mathrm{FeCl}_{3}$.

(VI) Static light scattering experiments used to determine the shapes and sizes of nanosize particles, which are in good agreement with light scattering and cryo-SEM.

\section{Acknowledgements}

Author wishes to thank Dr C Manohar, Mr PA Hassan and Mrs Janaky Narayanan for useful discussions and encouragement; Dr A K Sriraman for providing facilities; Dr J Bellare, B Kiran and M Haridas, IIT Bombay for their help in cryo-SEM and Prof. S D Samant, UDCT for useful suggestions; Dr Hemant Salunke for providing laser source. The author is also grateful to the Department of Atomic Energy (DAE), India for the financial support.

\section{References}

Aragon S R and Pecora R 1976 J. Chem. Phys. 642395

Ayyub P, Multani M, Barma M, Palkar V R and Vijayaraghavan R 1988 J. Phys. Chem: Solid State Phys. 21 2229 
Baily J K, Brinker C K and Mecortney M L 1993 J. Colloids \& Interface Sci. 1571

De Blanko E K, Blesa M A and Liberman S 1986 J. React. Solids 1189

Guinier A 1939 Ann. Phys. 12161

Guinier A and Fornet G 1965 Small-angle scattering of X-rays (New York: Wiley)

Hamada S and Matijevic E 1982 J. Chem. Soc. Faraday Trans. I 782147

Hamada S and Matijevic E 1990 J. Colloid \& Interface Sci. 137546

Henglein A 1987 Topics Curr. Chem. 143113

Kuo R J and Matijevic E 1980 J. Colloids \& Interface Sci. 78407

Matijevic E 1984 Proc. 49 Spring natl. meeting, ( The Chem Soc of Japan)

Matijevic E 1985 Ann. Rev. Mater. Sci. 15483

Matijevic E and Scheiner P 1978 J. Colloid \& Interface Sci. 63509

Morales M P, Gonzales-Carreno T and Serna C J 1992 J. Mater. Res. 72538

Morris R W, Lauer Jr H V, Lowson C A, Gibbson Jr E K, Nace G A and Stewart C 1985 J. Geophys. Res. 90 3126

Muench G J, Arajs S and Matijevic E 1981 J. Appl. Phys. 52493

Murphy P J, Posner A M and Qrirk J P 1976 J. Colloids \& Interface Sci. 54284

Nozawa Y and Yoneda Y 1980 Bull. Chem. Soc. Jap. 53648

Okana M, Morales M P and Serna C J 1995 J. Colloids \& Interface Sci. 17185

Ozaki M, Krathovil S and Matijevic E 1984 J. Colloids \& Interface Sci. 102145

Ozaki M, Ookoshi N and Matijevic E 1990 J. Colloids \& Interface Sci. 137546

Penner N H G and Koopal L K 1986 Colloids and Surfaces 19337

Quiben J and Matijevic E 1994 Colloids and Surfaces A82 237

Rayleigh-Gan Theory 1983 In absorption and scattering of light by small particles (ed.) C F Bohren (New York: Wiley)

Sugimoto T and Matijevic E 1980 J. Colloids \& Interface Sci. 74227

Schulz G V 1935 Z. Phys. Chem. 4325 